\title{
Aiding Global Public Policy: Rethinking Rationales and Roles
}

\author{
Robin Davies
}

Traditional development agencies, emerging aid providers, and recipient countries are in strong agreement that the fundamental purpose of aid is to help achieve the development priorities of sovereign states in need. This agreement serves both aid effectiveness and national interest objectives. At the same time, a range of global problems is rendering development gains ever more precarious and making increasing calls on aid budgets. Such problems include instability in highly integrated global markets for food, fuel, and finance, natural resource depletion, the persistence or emergence of infectious diseases, and the increasing impacts of climate change. Moreover, after growing by some 60 percent over the previous decade, global aid peaked in 2010 and now looks set to decline or at best stagnate, as most donor countries pursue fiscal consolidation and public debt reduction strategies and as more and more countries graduate from low-income status.

So now there is a fixed "lid" on aid, growing pressures to apply it to global challenges, and a dominant aid narrative that says it should be applied to the national challenges of the poorest countries. As argued in the previous chapter, at least one of these three things has to give, sooner or later. Either the purpose of aid must be reconceived, or more aid must be provided, or financing for global public goods (GPGs) must be mobilized in some new way without prejudice to existing aid budgets.

It is reasonable to assume that aid volume will not continue to grow at anything like the rate witnessed in the decade up to 2010 and that there is no realistic prospect that international public financing additional to current levels of aid will be mobilized on any significant scale by means of "innovative" financing mechanisms. Therefore, it must be concluded that if aid for GPGs is to be maintained or increased, the purpose of aid must at some point be reconceived-a corollary of which is that the institutions and instruments used to deliver it are likely to require a degree of modification in order to maintain their fitness for purpose.

This chapter proposes a relatively conservative modification of the rationale for aid, which carries implications for resource allocation, delivery mechanisms,

To see Robin Davies discuss global public policy aid: http://youtu.be/HdSJS4AH2XO 
the institutional and global governance of the relevant financial flows, and also to an extent for the measurement of those flows. It complements the previous chapter, but goes beyond posing a quandary to sketching the broad features of a possible way forward. The structure of this chapter is as follows. The first Section explores the formal definition of official development assistance (ODA) as it stands and finds that it can already accommodate a concept of aid that is somewhat broader, and more favourable to GPGs, than the concept currently in general use. The second section examines some obstacles that stand in the way of making greater use of the multilateral GPG delivery "system." The third section sets out in broad terms some proposals for overcoming these obstacles and for mobilizing and allocating financing for multilateral GPG-related efforts. The conclusion summarizes the foregoing discussion in the form of five general recommendations for action.

\section{Revising the Rationale for Aid and Redefining ODA}

There is at the time of writing a move afoot to "modernize" the concept of ODA. The 2012 High-Level Meeting of the Organisation for Economic Co-operation and Development's (OECD) Development Assistance Committee (DAC) determined that the DAC should "elaborate a proposal for a new measure of total official support for development" and "investigate whether any resulting new measures of external development finance ... suggest the need to modernize the ODA concept" (OECD 2012: paragraph 17). This move appears to have been driven by a desire, not necessarily to alter fundamentally the concept of ODA, but rather to achieve better recognition of other expenditures relevant to development and explore ways of including as ODA some expenditures that are developmentally motivated but not currently captured by the ODA definition. An example is providing official support for inclusive business ventures in low-income countries by means of guarantees and equity investments-which do not figure as "flows" or as concessional expenditures under the current ODA definition (OECD 2008). 1 There is also an ongoing debate about the ODA status of some official loans to developing countries-loans that are developmentally motivated and meet a technical grant-element test ${ }^{2}$ but are not actually concessional in character-in that the interest rate charged to recipients is above the donor's cost of borrowing, which is currently extremely low.

In short, the DAC's objective, or at least the objective of some of its members, is to tidy up the ODA concept by folding in some additional expenditures and pushing out others while at the same time investigating the use of a broader expenditure category that would incorporate ODA and capture total official support for development more fully, in some sense, than existing measures. Presumably, some donors calculate that if they fail to expand the ODA definition in the way that they might wish, they will still be able to incorporate the expenditures in question within the broader measure of total official support for development. It is conceivable that some DAC members would wish to exclude financing for GPGs, most notably climate change financing, from a revised ODA 
definition and include it instead under the broader concept of total official support for development. However, it is likely that an overwhelming majority of members would wish it to remain within the ODA category where, by default, it currently sits. The decision to revisit the ODA concept certainly does not appear to have been motivated by any broad-based desire to exclude GPG financing from ODA.

Just as there is no push to exclude financing for GPGs from ODA, there is no evident push to give it explicit recognition as a claim on ODA budgets. At present most such financing gets counted as ODA simply because it is generally provided in the form of grants to international organizations that are recognized as development organizations and generally ends up flowing on concessional terms to one or another country on the DAC's list of ODA-eligible countries, which excludes only high-income countries. $\underline{3}$

Even grants to the Global Environment Facility (GEF), established with the explicitly limited aim of financing national and regional project costs only insofar as they yield global benefits, are 100 percent reportable as ODA. ${ }^{4}$ Some core funding for international organizations that have a substantial normative function - such as the World Health Organization, the UN Food and Agriculture Organization and the International Labour Organization-is excluded from ODA and is generally drawn from the budgets of the relevant domestic ministries in contributing countries, but the amount of money concerned is not large. The vast bulk of international public financing for GPGs comes from ODA.

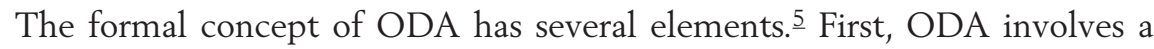
flow of resources from the official sector, either from a developed to a recognized developing country or from a developed country to a recognized international development organization. $\underline{6}$ Second, the flow must have the "main objective" of promoting the economic development and welfare of developing countries. Third, it must be concessional in character, meaning that it must incorporate a subsidy. If the flow takes the form of a loan, the loan must be equivalent to a grant worth no less than 25 percent of its face value, and principal repayments figure as negative ODA in the year in which they are made. ${ }^{7}$ ODA is fundamentally aid as given by donors. Measuring ODA measures donors' fiscal effort. It does not measure aid as experienced by recipients, $\underline{\underline{8}}$ both because much ODA does not actually cross borders and because some ODA is not passed on to developing countries in concessional form by some international organizations. $\underline{9}$

The ODA definition looks to be quite narrow in two respects. First, it would appear at first glance to exclude expenditures that benefit developing countries but do not involve cross-border flows, such as expenditures on aid administration and on universities that might in some cases educate students from developing countries at less than full cost. Second, it also appears at first glance to exclude expenditures related to GPGs that are primarily of benefit to people in or from developing countries, such as research undertaken by developed countries' national research institutes into neglected tropical diseases or smallholder agricultural productivity, and, controversially, costs associated with the presence in developed countries of refugees and asylum-seekers from developing countries. 
However, in practice the DAC has taken a series of ad hoc decisions that have incorporated these and other expenditures within the category of ODA by fiat. The core of the ODA concept has not, in that process, been revisited. As already noted, recent moves to "modernize" the concept seem unlikely to involve fundamental reconsideration of the ODA definition.

What notion of aid, then, would be more conducive to the allocation of an adequate amount of aid for GPGs? (Rather than seeking to quantify "adequate," we simply assume that an adequate amount would be equal to or greater than the present amount.) Broadly speaking, such a notion might have several features. First, it would still be a notion of aid, not of something much broader, such as "official global public finance." 10 That is, it would relate to public expenditures that are primarily for the benefit of developing countries, including expenditures on GPGs important for development. Second, it would recognize the fact that international organizations are in themselves GPGs, as well as mediums for the provision of GPGs through action in developing countries, and would give effect to this recognition by counting as aid all contributions to a defined group of international development organizations, regardless of the specific utilization of those contributions. Third, it would incorporate a concessionality requirement, but allow that contributions to some international development organizations might be used by those organizations to fund non-concessional expenditures with a developmental objective.

Would this be a very substantial departure from the concept of aid embodied in ODA? In fact, it would be no departure at all. It is quite possible within the existing formal definition of ODA to give substantially greater prominence to financing for GPGs through international organizations. It is common but not entirely correct to regard ODA as a flow to developing countries, with multilateral organizations functioning as one channel for ODA flows. On more careful examination, the ODA concept gives multilateral organizations a more privileged role than that. ODA is defined as "those flows to countries and territories on the DAC List of ODA Recipients and to multilateral institutions which are provided by official agencies ... and each transaction of which is administered with the promotion of the economic development and welfare of developing countries as its main objective; and is concessional in character" (OECD 2008). The institutions mentioned are, like developing country aid recipients, identified in a separate list that is regularly revised. So, putting the point very roughly, to fund multilateral organizations to do whatever they do is to provide ODA, by definition. Some of their outflows do not meet the ODA definition, but that has no bearing on the ODA status of contributions to them.

It would perhaps be less confusing if concessional outflows from international organizations were not labeled as ODA in statistical reporting, such that the term "ODA" were applied only to outflows from original sources, and a term like "official development finance" (ODF), or country programmable aid (CPA), or something else that measures aid received, were applied to inflows to developing countries. However, the key point is that the existing concept of aid in fact is not unfriendly toward aid financing for GPGs. There is certainly no need to turn the 
tables by replacing the concept of ODA with that of official global public finance (as above) or some similar construct.

The central idea at work here, requiring no change in the formal concept of ODA, is to change the way we think about international development organizations, which play an indispensable role in supporting the provision of GPGs through their global-, regional- and country-level work. Rather than thinking of such organizations primarily as channels for aid to developing countries, we may think of them primarily as objects of aid in their own right. Essentially, funding to them is aid if their mandate is developmental.

The notion of aid outlined above involves not a change in the formal concept of aid, but rather a change in the rationale for, or the narrative about, aid. This change would involve moving to a two-part, public good rationale for aid. According to this rationale, aid supports the provision of national public goods $\underline{11}$ for growth and poverty reduction $\frac{12}{}$ and the provision of regional and GPGs to meet transnational challenges of particular importance for developing countries. Funding for international development organizations would be considered to inhabit the latter category, even where their country-specific operations are concerned. Thus, roughly speaking, bilateral aid (aid to countries) would be about national public goods; multilateral aid (aid to international development organizations) would be about GPGs.

If strictly accepted, this approach would have substantial implications for the way one would think about, and in fact manage, the operations of both bilateral and multilateral agencies. One implication is that it becomes unimportant and indeed unhelpful to distinguish so sharply between the hard and the soft arms of the multilateral development banks (MDBs). Currently it is the case that all capital and grant contributions to the World Bank Group are considered aid and that outflows from the International Development Association (IDA), but not from the International Bank for Reconstruction and Development (IBRD), $\underline{13}$ are considered aid. IDA, under the approach proposed above, would no longer be described, as it is now, as the "aid agency" of the World Bank Group, because its outflows would be treated in the same way as IBRD outflows for accounting purposes - in the "development financing received" category.

A second implication is that given an explicit license or even a mandate to concentrate more of its resources on the provision of GPGs, consistent with the above notion of aid, the World Bank would be better able to offer incentives to clients in the form of flexible financing packages, blending funds borrowed against its capital and funds received from donors in grant or at least concessional form. At present, such blending is practiced mainly in order to achieve financing terms of intermediate hardness for countries graduating from IDA to IBRD financingthough it has also been practiced to some extent in connection with global environmental public goods, through the blending of GEF resources or resources from the Climate Investment Funds (CIFs) with resources from the nonconcessional arms of the MDBs. The same approach would be open to other MDBs.

A third implication is that the job descriptions of both bilateral and multilateral development agencies would be sharpened considerably. Bilateral 
agencies - in line with the two-part, public good rationale outlined above-would be less likely to attempt direct support for the provision of GPGs and more likely to provide such support through the multilateral system. Multilateral agencies, and particularly the MDBs, might well continue to be strongly oriented toward support for the priorities of sovereign states but, with an explicit GPG mandate and more flexible financing instruments, would seek to select and manage their investments in a way that is consistent with the objectives of an overarching GPG strategy.

The two-part rationale offered here, like any rationale for aid, faces an important test: Would it weaken public and political support for aid? It seems unlikely that it would do so. For one thing, it is still recognizably a concept of aid, unlike the alternative concept of official global public finance. If anything, it sharpens the focus of bilateral aid on poverty reduction. Further, it gives a clearer account of the role of international organizations, which at present are often perceived either as servants or competitors of bilateral development agencies. Finally, it does not take multilateral organizations away from country-based work, on which their influence and credibility partly depends, but it does add a higher, global purpose to that work. This last point is important from a substantive perspective too: It is a mistake to think that all GPGs can be provided in a sort of global ether. Many such goods, as noted in the previous chapter, are provided in a cumulative fashion-through coordinated or replicated action across multiple countries, supported where necessary by advice and incentives.

\section{The Multilateral GPG Delivery System}

Is the multilateral GPG delivery "system" actually up to the task proposed for it above? Even if more public finance were supplied for GPGs, and even if this use of public finance met with no resistance from any quarter, there remains the question of whether the multilateral system is well adapted to support the production and adoption of GPGs important for development. There are several reasons to believe that it is not. These relate broadly to an absence of overarching strategy, a failure to integrate efforts in various ways, a bias toward some types of GPG at the expense of others, and an unsystematic approach to evaluation and learning.

\section{The Strategic Deficit}

With one exception, there has never been an attempt to organize the work of international organizations, let alone development agencies in general, in support of GPGs. Priorities and mechanisms have for the most part emerged piecemeal. This is reflected in the composition of the World Bank's portfolio of global and regional partnership programs, which number some 120. It is reflected also in the array of mechanisms that contribute to the achievement of global health objectives, as well as the growing stable of mechanisms that seek to achieve climate change mitigation or "green growth" objectives. The exception just noted is the Consultative Group on International Agricultural Research (CGIAR), 
which is trying to implement a strategic approach to the definition of research priorities for, and the allocation of resources to, its 15 affiliated research centers. Even here, though, there is considerable uncertainty about the extent to which individual donors and individual centers will cooperate in a sustained manner.

Outcome-oriented financiers, particularly private foundations, will often perceive cross-institutional strategies as straitjackets or disdain the bureaucracy associated with centralized resource allocation. One reason for this is the view that centralization and bureaucracy are antithetical to innovation-that modular, nimble, and competing approaches are better able to achieve results where innovation is needed. To make matters worse, individual bilateral donors for the most do not themselves have GPG financing strategies. In allocating resources to global programs, they tend to finance the priorities of today, often at the expense of the priorities of yesterday. The World Bank, which plays a central role as trustee for the majority of the donor funds allocated to global mechanisms, also has no explicit policy basis for determining which GPG-related priorities should be primary, taking into account likely development impacts, the scale of resourcing likely to be available, and its own institutional capabilities. Its 2007 GPG policy framework does not serve this purpose and cannot have been intended to do so.

Often the strategic deficit described above is evident even within single sectors, most notably that of global health. It is not possible, for example, to discern any logic underlying the distribution of resources between mechanisms such as the Global Fund to Fight AIDS, Tuberculosis and Malaria (GFATM), the GAVI Alliance (formerly the Global Alliance for Vaccines and Immunisation), the 2006 pilot Advance Market Commitment for pneumococcal vaccines, and the many product development partnerships working on vaccines, drugs, and diagnostics. $\stackrel{14}{4}$ The 2001 Commission on Macroeconomics and Health (WHO 2001), it should be acknowledged, did provide reasoned recommendations relating to the allocation of resources for public health, including resources for GPGs. The commission argued for the allocation of $\$ 7$ billion in ODA per annum to GPGs in the health sector, within total health sector spending of $\$ 38$ billion by 2015. It also provided a breakdown of how these resources might be used. However, there is no evidence that its GPG-related recommendations achieved any impact beyond the creation of the GFATM.

\section{Fragmentation of Effort}

GPG financing mechanisms are extremely numerous and for the most part small and issue specific. The mean fund size for the global and regional partnership funds in which the World Bank is involved is $\$ 58$ million, given a total of $\$ 7$ billion across 117 funds (IEG $201 \mathrm{lb}$ : table 2.1). The median size is not known but would be much lower, as most funds are quite small-86 percent of the money is in one-quarter of the funds. Only a handful of GPG mechanisms are substantially larger, most notably the "big five": the GEF, GFATM, GAVI Alliance, CGIAR, and the CIFs.

The GPG financing mechanisms with which the World Bank is associated have tended to emerge incrementally; 15 for every problem, or set of closely 
related problems, a fund is formed with associated governance arrangements, resource (usually grant) allocation processes, and administrative support structures. They are incremental in other senses too. First, they are generally separate from and supplemental to the country operations of the Bank and other development agencies. And second, in some cases they provide resources to countries only for the incremental costs of delivering global benefits. While the concept of incremental cost is clear enough, actually calculating the level of such costs for resource allocation purposes has proven to be difficult. In fact, it has been judged ultimately unproductive by the GEF, which in 2007 retreated to the much looser requirement that investments be based on "incremental cost reasoning" rather than incremental cost assessment.

The fragmentation and the related incrementalism described above inflicts quite high transaction costs on the countries that might benefit from GPG financing mechanisms, as well as the organizations that host them. Those costs include, most importantly, a diversion of attention away from the main strategic priorities and decision-making processes of the relevant government or organization.

It might be argued that economies of scope are important in the production of GPGs, such that numerous mechanisms should be tolerated rather than seeking to overconsolidate. The point made earlier about the importance of diversity and competition in spurring innovation is also relevant here. However, it seems beyond doubt that in many cases GPG financing mechanisms, without good reason, have taken on lives of their own, becoming in effect new microdevelopment agencies that compete for the attention of donors and partner governments.

For the most part, then, GPG financing mechanisms do not occupy a central place in either the mainstream operations of country-oriented international development organizations or in the national development strategies of partner governments. Real complementarity-that is, coordination and mutual reinforcement-between these mechanisms and those that finance national public goods is absent. However, partial exceptions to this observation exist in the case of larger mechanisms. The GFATM, for example, wields enough market power to influence the allocation of complementary resources by donors. In addition, both the GFATM and the GAVI Alliance have broadened the scope of their investments over time in response to criticisms that they did not sufficiently recognize the importance of health system strengthening at the national level. And the GEF by design employs cofinancing, blending its resources with those from mainstream sources. These instances of complementarity are described as partial, however, because from the developing country perspective there are still many actors and products in play, with correspondingly high transaction costs.

The case of the CIFs, in particular the Clean Technology Fund (CTF), bears closer examination. By contrast with the situation in the GEF, in the CTF cofinancing is more an operating principle than a requirement. For reasons of speed and efficiency, the CTF has allocated resources as far as possible in conjunction with mainstream IBRD and IDA operations, or the equivalent 
operations of other MDBs, using those resources to generate incentives for lowemission investments. CTF funds are used to soften the terms of, or grant-finance discrete components of, larger financing packages-which is attractive both to geographic departments of the MDBs and to their customers.

While the GEF's 2007 shift to incremental cost "reasoning" effectively made its investments complementary in the same sense as the CTF's, there is an important difference. Although technically part of the Bank, the GEF is its own institution, whose involvement in a transaction adds greatly to processing times and transaction costs for all parties. It is not merely a pool of resources that can be blended with others. The CTF, admittedly, is not exactly the latter either, as it has its own governance arrangements. Nevertheless, the way it is managed does provide a higher degree of complementarity with mainstream MDB operations than is typical of other GPG financing mechanisms. This strength of the CTF model is, at the same time, also a source of weakness. The CTF's light management arrangements mean that it is at the mercy of the vagaries of demand from geographic areas of the participating MDBs. It has limited capacity to generate such demand or to establish and enforce internal accountability arrangements within the banks for activities already approved.

The underlying problem with existing GPG financing mechanisms is that they exist at the margins of their host institutions, such that they are either good at complementarity but organizationally weak or less good at complementarity but organizationally stronger. Ideally, their priorities would be central priorities of their host organizations. Were that the case, aggregating resources in GPG financing mechanisms might not always be necessary. In principle, at least for cumulative GPGs, it might be sufficient simply to use existing country-oriented financing mechanisms and instruments, but with a modified approach to program selection that favors programs with greater global benefits over those with lesser benefits and seeks to support coordinated or parallel interventions in multiple countries.

\section{Bias Toward Some Global Public Goods}

The existing array of GPG financing mechanisms tends to favor certain types of GPG, namely, those described in the previous chapter as "singular" and "structured" GPGs. There is considerable, if still inadequate, resourcing for agricultural and health research for the production of singular GPGs. There is much support for global and regional institutions that mediate international cooperation on a regional or topical basis to produce structured GPGs. But there is much less in the way of support for the provision of cumulative GPGs, which depend on serial or parallel action in all countries that are particularly important for the solution of a problem. The Multilateral Fund of the Montreal Protocol, which supports developing countries in eliminating ozone-depleting substances, is one example of a GPG financing mechanism for a cumulative GPG. World Bankmanaged mechanisms, such as the Forest Carbon Partnership Facility, the Forest Investment Fund, and the CTF, are other examples, though they are only conceived as pilots and do not claim to be able to take in a large number of the 
important countries, whether considered as such for their impact on emissions from deforestation or from energy generation.

The imbalance noted here is not an arbitrary one. Singular and structured GPGs are suitable for stand-alone funding, which can be provided directly to the singular producer or to the structuring institution. Cumulative GPGs can only be provided through mainstream operations, drawing as necessary on concessional resources for incentive purposes. Thus priorities and mechanisms that are perceived and often conceived as marginal to those operations are of little relevance to the provision of cumulative GPGs.

\section{Evaluation and Learning}

GPG financing mechanisms are often individually well evaluated. The GEF, for example, has a strong evaluation office and is also evaluated indirectly by the World Bank's Independent Evaluation Group (IEG), which regularly examines the quality and impact of the Bank's partnerships with global funds. The major global health mechanisms are also closely scrutinized and again also indirectly by the IEG. The CIFs are at the time of writing the subject of a major evaluation, which will make findings on impacts achieved and lessons learned since the establishment of the CIFs in 2008. The CGIAR system was fully evaluated by the IEG in 2004, and the findings of that evaluation were important in shaping the systemic reforms subsequently put in place.

However, there is a deficiency at the level of strategic and comparative evaluation. This can be seen, for example, in the way that World Bank-related GPG mechanisms were, in a sense, evaluated twice over-through the IEG's twin, overlapping 2011 evaluations of the Bank's involvement in global and regional partnership programs (IEG 201 lb) and of its trust fund portfolio (IEG $2011 \mathrm{a}$ ) yet not evaluated in a way that specifically considers the impact and coherence of the Bank's involvement in GPG financing mechanisms.

There has been only one dedicated effort to assess the World Bank's work in support of GPGs-the IEG's 2008 Annual Review of Development Effectiveness, which took as its special theme "shared global challenges" (IEG 2008). However, this review reached quite broad and predictable conclusions about the disconnect between country priorities and global priorities. It did not make actionable recommendations as to how the Bank might better marshal its resources-IBRD, IDA, International Finance Corporation (IFC), and trust fund resources-in support of GPGs. Its recommendations set out no operationally specific policy framework for such investments and, therefore, represented no advance on the Bank's own 2007 framework. No other MDB has even attempted something comparable to the IEG's 2008 exercise.

Individual bilateral donors likewise do not conduct comparative evaluations of the GPG financing mechanisms they support. Their mechanism-specific evaluations tend to be directed toward those mechanisms in which, for often purely accidental reasons, they already have a significant financing stake. This multilateral and bilateral evaluation deficit mirrors the strategy deficit already discussed. 


\section{A Way Forward}

What follows takes a more constructive turn. It is suggested that a number of measures would need to be taken in order to make the World Bank, other MDBs, and other multilateral organizations fit as GPG delivery mechanisms. Those measures, set out in general terms below, include rethinking financing instruments and programming strategies; reforming policy and governance frameworks; aligning country and global priorities; streamlining the mobilization and allocation of concessional financing for GPGs; and managing for impact.

\section{Rethinking Instruments and Strategies}

Suppose that the World Bank has at its disposal a substantial, IDA-like pool of concessional resources to supplement the resources it can raise on its own account. Suppose also that this pool of resources, unlike IDA, is available for use in any developing country. The question then is how might all the Bank's financial resources be deployed so as to achieve a meaningful impact on key global challenges? The answer suggested below involves three strategies: blending, replication, and leveraging.

Consider first the concept of blending - that is, the blending of concessional and nonconcessional resources within financing packages. At present, as noted earlier, blending is used primarily to wean countries off concessional financing, though it has been used to some extent to create incentives for action on global environmental public goods in the past and also to promote food security in the aftermath of the food price crisis of 2007-08, via the Global Agriculture and Food Security Program.

The latter type of blending is not much remarked upon, perhaps in part because it tends to involve the spending of concessional resources in middleincome countries rather than low-income countries. (Countries in the latter category will generally not accept financing on nonconcessional terms, even with blended packages.) However, there is clearly considerable scope to induce action on GPGs through the provision of financing on sufficiently favorable terms, as has been demonstrated by the experience of the CIFs.

Here "sufficiently favorable" means simply favorable enough to persuade a government to opt for a better alternative over a worse one, in circumstances where the better alternative helps to supply a GPG and the worse one would have been acceptable to the government in question when considered in purely national interest terms. This is quite different from an approach where financing terms are determined by the characteristics of the borrower or of the investment itself, and also from an approach that seeks to limit the use of the concessional component of the package to support for the "incremental" costs of supplying a global benefit. What is here proposed is rather that the concessional financing be used, as sparingly as possible, to create incentives for action.

Now consider the concept of replication-that is, the replication of programs across countries to achieve a sort of domino effect, spreading impact but also 
creating shared and linked strategies that are mutually reinforcing. This happens now on an ad hoc basis-for example, in the case of support for smart energy grids or rapid urban transit systems - but there is at present no strategic approach to replicating programs, within or across major multilateral organizations, for the purpose of increasing the supply of GPGs.

There are few incentives to do this. MDB staff would generally prefer to be known for creating blueprints than for applying others' blueprints, and their clients are on the whole resistant to investment proposals that appear to be driven by the financier or cut-and-pasted from other and quite different country contexts. However, deliberate and strategic replication would seem to be essential if cumulative GPGs are to be supplied in sufficient quantities. Programs with similar objectives need to be supported in multiple countries, and those programs should as far as possible have similar characteristics for reasons both of efficiency and mutual reinforcement.

And now consider the concept of leveraging - which is here intended to refer not merely to cofinancing but rather to the use of concessional resources to mobilize private investment for large and decisive impacts. ODA accounts for only about 7 percent of the total flow of resources from developed to developing countries (DI 2013), and cannot by itself achieve such impacts. It must wherever possible be combined with, and influence the allocation of, non-ODA flows. At present ODA is used to create incentives for private investment in at least five distinct ways:

- It funds risk reduction (by providing equity, quasi-equity and guarantees).

- It backs the issuance of bonds to finance large-scale, high-impact development interventions that promise to deliver long-run savings net of repayments to bondholders (the International Finance Facility for Immunisation, or IFFIm, being the only significant example of this approach to date).

- It provides, through "pull mechanisms," price incentives for investment in the discovery, development, and dissemination of products important for development (examples of which include the Pneumococcal AMC vaccines and the AgResults initiative).

- It helps developing countries participate in international permit trading mechanisms associated with the pricing of externalities (for example, the Clean Development Mechanism [CDM] or arrangements aimed at reducing emissions from deforestation and forest degradation and enhancing forest carbon stocks [REDD+]).

- It funds the public side of public-private product development partnerships (such as the Medicines for Malaria Venture [MMV] and other Geneva-based health sector partnerships).

A further possibility, which combines elements of the second and third approaches above, is the use of aid to back the issuance of "impact bonds," where returns to investors, and therefore costs to donors, vary with the results achieved. $\underline{16}$ 
In addition to its support for risk reduction through the World Bank Group's IFC, which for the most part is not provided in the service of GPGs, the World Bank has been involved in a number of GPG-related efforts that fall into categories above, namely, the carbon funds, the Pneumococcal AMC vaccines and the G20-endorsed AgResults initiative (a pull mechanism that seeks to stimulate private sector innovation in smallholder agriculture), all of which seek to create the conditions for market-based investment in, or for the benefit of, developing countries-either by helping to establish new markets (carbon) or correcting market failures (vaccines and agricultural products). The Bank has acted as trustee for IFFIm, a front-loading initiative that raises funds for immunization through the issuance of bonds backed by long-term ODA pledges. In addition, the Bank has been involved in some push-financed product development partnerships, though it is less clear what it has to offer in this effort. $\frac{17}{}$

Overall, the Bank's main attempts to engage the private sector in the provision of GPGs are of two broad types - those aimed at creating markets for products that help to yield GPGs and those aimed at securitizing anticipated aid flows in order to achieve immediate and decisive impacts. And corresponding to the two broad forms of leveraging just identified are two facts. First, action on global challenges that is taken in developing countries will yield greater benefits per unit of investment, given their cost advantage, than action taken in developed countries-which creates opportunities for trading where regulatory regimes permit. Second, action taken now will yield greater benefits, given its prevention potential, than action taken later.

These facts are rather straightforward and compelling, yet the various initiatives described are essentially all pilots, and none is large scale relative to the problem that it seeks to address. They have mostly been perceived as experiments in innovative financing, rather than as major efforts to make inroads into global problems or problems affecting developing countries in general. ODA for GPGs is heavily concentrated on public investment, with relatively short-term investment horizons. There might therefore be a good case for establishing a target for the share of any given ODA pool that should be devoted to the mobilization of private investment in GPGs. A target for the level of such investment itself would be very difficult to select and measure.

So, given a pool of concessional resources that can be allocated without restriction as to geography, country income (below the high-income threshold), or sector, the best way to achieve impacts on global problems is likely to be as follows. First, use concessional resources as incentives to influence investment decisions, by blending them with nonconcessional resources to deliver sufficiently attractive financing terms. Second, seek to replicate investment programs and associated financing arrangements across countries so as to achieve cumulative impacts with maximum efficiency and connectedness. Third, use concessional or blended financing in a much more determined fashion to facilitate private investment that contributes to the provision of GPGs, perhaps based on a target for the share of the ODA pool that should be used to facilitate such investment. 


\section{Strengthening Strategy and Governance}

There are no effective global or institution-specific frameworks for action on GPGs. The World Bank's 2007 framework (World Bank 2007) does little more than indicate broad priority areas, of which there are five: preserving the environment; controlling communicable diseases; strengthening the international financial architecture; enhancing developing countries' participation in the global trading system; and creating and sharing knowledge relevant for development. The choice of areas may be questioned but, more importantly, the framework gives no indication of how or to what extent the Bank will seek to contribute in each of the areas identified. It is essentially a general policy statement, not an operational framework. Other institutions offer the same or less, so it is not surprising that there is nothing at all at the supra-institutional level. The existing supra-institutional development framework is by default that articulated in the Millennium Declaration (UN 2000) and subsequently elaborated in the Millennium Development Goals, but that framework gives muted treatment to GPGs and does little to create incentives for the allocation of ODA in support of them.

With the elevation of the G20 to become a leaders-level forum in the aftermath of the global financial crisis, and the adoption by the G20 in 2010 of a development "agenda" (G20 2010), one might in principle expect the G20 to play a role in establishing a supra-institutional framework for the provision of GPGs. However, that seems a distant prospect at present, given the way in which the G20's development agenda has unfolded to date. In the absence of any supra-institutional process, it would be desirable for the World Bank's Board of Directors to request that the Bank's 2007 framework be revisited, seven years on, and made much more operational as well as more relevant to today's challenges. As part of this process, two distinct but related needs should be met, as follows.

First, the current array of global and regional partnership programs, which are perceived as the Bank's primary way of contributing to the supply of GPGs, needs to be placed on a clearer strategic footing. This would facilitate some consolidation of these programs, something that is obviously needed but difficult to achieve in the face of donors' special interests and requirements. It needs to be recognized explicitly that partnerships are not the only vehicles for contributing to GPGs. Several large financial intermediary funds have the same objective, but are not considered to be part of the above constellation, falling instead into the general category of trust funds. A strategic framework is needed for all trust funds that contribute to the supply of GPGs.

Second, and more importantly, the manner in which country operations are expected to contribute to the Bank's objectives in this area requires clear and forceful articulation. At present, any such contribution is either largely a by-product of investment decisions made for national or mutual interest reasons or is dependent on the will of individual staff to make use of the limited concessional resources available to support investments in GPGs through country programs. There is nothing that resembles a set of targets for 
such investment. There are no positive incentives for individual staff to steer their clients in this direction, and there are no procedural requirements to seek to replicate and network successful investments across countries. The overall absence of incentives and accountability mechanisms that might ensure any particular level of investment in GPGs is perhaps understandable when the Bank has only quite rigid financing instruments at its disposal, but the situation could be quite different if the Bank were able to offer more flexible financing packages.

The likely emergence of a BRICS (Brazil, Russia, India, China, and South Africa) bank-combined with calls for the creation of a new global "infrastructure bank"18 — might be seen to pull the World Bank even more strongly toward responsiveness to national priorities. However, the opposite conclusion can as easily be drawn - that any new institutions of the kind proposed (which are at the present time very far from becoming realities) would relieve pressure on the Bank's resources and allow it to reposition itself as an institution seeking to find and work at the intersection of national and GPGs.

\section{Aligning Country and Global Priorities and Programs}

As has been noted above, the Bank's primary contribution to the supply of GPGs is likely to be through its country operations. So, in addition to having a strategic framework that ensures consistency between country and global priorities, it would be important to ensure that global programs are connected to and directly support country operations and that country operations are mandated to make use of the concessional resources available in global funds. Of course, the extent to which this might be achieved depends in large part on the flexibility of donors, who will not always welcome the loss of identity involved in blending their trust fund resources into country-level investment packages.

\section{Mobilizing and Allocating Concessional Financing for Global Public Goods}

The discussion above has assumed, for the sake of argument, the availability of a pool of concessional resources that might be allocated to developing countries, without restriction as to geography or income level, for the purpose of contributing to the supply of GPGs. Even if this unrestricted approach is seen as unrealistic or insufficiently targeted, a clearly identifiable and bounded pool of resources would be a prerequisite for effective action to supply GPGs for development. Unless a specified quantity of resources is reserved for allocation to such GPGs, other uses will predominate, as this is in the nature of GPGs. The question is how such a pool might be created and managed.

One option is obvious, though not without problems. That option is to use the IDA. IDA is, as noted earlier, losing clients at a significant rate. This fact presents IDA's donors with three choices. They can cut IDA back, increase allocations to the remaining IDA-eligible countries, or keep the graduation dividend within IDA but use it for something other than operations in low-income countries-namely GPGs. GPGs, like poor countries, need grant financing. 
This option, however, has two substantial problems. One is that IDA is strongly identified as the World Bank's fund for the poorest countries, and the loss of this clear identity could have a negative impact on perceptions of the Bank generally, even if the GPG component of IDA is quarantined. Another is that IDA is subject to the Bank's normal governance processes, which are unlikely to deliver more than marginal adjustments to IDA's country-based operating model.

There are two equally obvious alternatives to the IDA option. One is to create a parallel GPG fund within the World Bank Group on the model of IDA and to seek, at a minimum, to divert the IDA graduation dividend into this fund. The other is to create such a fund outside the Bank (which would not preclude the Bank's acting as trustee) but with a strong connection to the investment pipeline of the Bank and other MDBs, as well as to the project pipelines of certain other grant-based international development organizations. The former option is subject to the same reservation as the IDA option with respect to institutional governance: it is simply unlikely to happen. The latter option has much merit but faces a much greater challenge in capturing the IDA graduation dividend.

Leaving aside the latter challenge, the principal merit of creating an external mechanism is that it could be set up with governance arrangements that are both fit for purpose and reflective of the stakes that major countries, and perhaps other actors, have in the problems to be addressed-rather than of the amount of funding they might have contributed to the fund. It need not constitute a new international organization: it could be a fund on the model of the CIFs, whose board determines strategy, approves major investments, and monitors progress and impact, but whose administrative support structure, including the treasury function, might be provided by the World Bank.

In addition, an external mechanism need not establish direct funding relationships with governments or private sector actors. In an already crowded field, it would preferably channel its resources through existing institutions, supporting them to develop and executive GPG strategies. A further benefit of externality is that the fund could have associated with it an independent policy hub, which might assist in the development of both institutional and cross-institutional strategies for the supply of GPGs. Its leadership could also take on certain functions that presently reside within the Bank by default, such as coordination of the CGIAR system. It might be argued that the Green Climate Fund (GCF) should have developed according to this kind of model, rather than aspiring to become a self-contained institution, and in fact, it is currently quite uncertain that it will succeed in becoming the latter.

While resource mobilization for such a fund could proceed on the IDA model, which involves regular injections of concessional resources through negotiated replenishments, consideration could be given to folding into it many existing trust funds and also raising resources on the IFFIm model through the issuance of aid-backed bonds. For any new resources, burden-sharing arrangements would be challenging to negotiate, and traditional donors might need to tolerate 
a mismatch between voting power and cash contributions. To reduce this mismatch somewhat, developing countries might be allowed to count toward their shares the cost of domestically financed measures that contribute, either wholly or in part, to the supply of GPGs.

\section{Managing for Impact}

It is a particular, if not unique, feature of GPG financing mechanisms that funds and partnerships are established with considerable fanfare in connection with a recognized problem, but without any clear targets or theories of change. Certainly it is difficult to "size" such funds and partnerships a priori or devise plausible, realistic theories of change when action involves multiple actors and complex problems. But for these reasons, it is all the more important that a strong impact-monitoring regime be put in place. Strong impact monitoring is the flip side of a strong institutional GPG strategy: the two things are interdependent.

A robust independent evaluation function established in association with the financing mechanism sketched above, and reporting to its governing body, could examine the performance of all institutions receiving funds, individually and collectively. It should specifically examine their performance in supplying GPGs, not merely in managing partnership programs or trust funds. It might subsume, but need not do so, the capable, independent Evaluation Office of the GEF.

\section{Conclusions}

By way of summarizing this discussion, what follows is a set of broad conclusions regarding the role of international public financing in supporting the provision of GPGs_or, more concisely, financing global public policy.

Essentially, the argument made here has been that there is no need to redefine what constitutes aid in any technical sense-or make any dramatic changes in the way in which it is measured-in order to facilitate its use for financing global public policy. Aid is not bound to be provided as a flow of resources to countries. What is more likely to be needed, sooner or later, is a new rationale for aid that assigns it a dual role: financing national public policy and financing global public policy. An important element of this rationale is that global public policy is the domain of global institutions, so that this second purpose of aid entails a strengthened role for such institutions, and also very material changes in the way in which they conduct and present their operations.

By way of summarizing the main points made in this chapter, five concluding recommendations are set out below, then briefly elaborated upon.

- adopt a new, bifurcated rationale for ODA;

- develop strategic institutional frameworks for financing global public policy;

- pursue global goals through country operations, as well as global programs; 
- shift to the use of more flexible financing packages to create incentives for deviations from business as usual; and

- establish a global financing facility to finance global public policy through existing institutions.

\section{A New, Bifurcated Rationale for ODA}

The international development community should change the rationale for ODA, not the definition of it. The existing ODA definition is interpreted too broadly in some ways, but too narrowly in others-certainly too narrowly with respect to GPGs. It is in fact capacious enough to support, without change, a new, bifurcated rationale for aid that gives much greater prominence to the role of international development organizations as agents for the supply of GPGs, rather than merely as agents for the delivery of bilateral resources. According to this rationale, the purpose of aid is to support both national and GPGs, where support for GPGs is provided through the multilateral system.

Outflows from international development organizations are best not conceived as aid in the above sense, though many of them will meet the concessionality requirement. They are already captured in the concept of official development finance, a measure of financing received by developing countries rather than a measure of aid given by donors, and are best considered in that category. The ODA concept's principal value is as a basis for assessing and motivating fiscal effort on the part of sovereign states.

\section{Frameworks for Financing Global Public Policy}

International development organizations should adopt institutional strategies for contributing to the supply of GPGs through both country and global programs. These should as far as possible be linked across key institutions and certainly across the MDBs. They should be more than policy statements: they should be operational strategies that set goals, drive resource allocation, articulate implementation arrangements, and provide a basis for monitoring and evaluation.

Such strategies should lead to a consolidation and rationalization of the existing patchwork of arbitrarily sized and unreliably funded global and regional funding mechanisms operated by the World Bank and, to a lesser extent, other MDBs. The impact of approaches and instruments tried to date needs to be more systematically assessed so as to support decisions about which to replicate and scale up and which to discontinue.

The G20 has a unique capacity to ensure that linked institutional strategies are developed, resourced, and implemented. It also has an obvious role in monitoring the supply of GPGs important for global stability and prosperity. This could become an important theme of its development agenda as that agenda further evolves. 


\section{Global Goals through Country Operations}

From a sustainability perspective, the most important GPGs are not those that can be supplied by means of relatively small funds and tight-knit coalitions of like-minded organizations. Tiger preservation might be supplied in that way; climate change mitigation clearly will not be. The most important GPGs will be supplied by governments and private actors through cumulative action across multiple countries.

It is of paramount importance to create incentives for the pursuit of GPGs through mainstream country operations, rather than merely through global programs. Incentives are needed for clients and for World Bank staff, particularly in middle-income countries, which now have a much wider range of financing options than previously.

More generally, the way in which the Bank conceives its mission needs fundamental reconsideration. Its goal should increasingly be to find and work at the intersection between national and global public policy priorities.

\section{Flexible Financing Packages}

MDBs should be enabled and mandated to offer flexible financing packages to clients, packages that provide sufficient incentives to undertake or modify investment intentions in favor of GPGs. These might blend concessional and nonconcessional resources in various degrees, with the blend determined not by the characteristics of the borrower or the operation, but by the level of incentive required to reach agreement in a particular case.

Allowing calibration of incentives would increase the MDBs' capacity to pursue global goals through country operations. Even where blending results in the provision of a "soft" financing package, the package should not be characterized as aid. It should be considered as ODF of a piece with non-concessional lending.

\section{A Global Financing Facility}

A dedicated GPG financing facility—a Global Financing Facility—should be established at arm's length from any existing institution, but using existing administrative structures and financing channels.

In addition to its financing function, the facility should be equipped with strong policy advisory and evaluation functions. It should be financed by folding in resources from a range of existing funds, possibly including the GCF, if that fund proves unable to get off the ground, as well as by raising cash contributions from donors and by raising funds in the capital markets through the issuance of bonds backed by long-term ODA pledges. $\underline{19}$

The Global Financing Facility should be required to allocate a defined proportion of its resources to the mobilization of market-based investments in GPGs. Its governance arrangements might include government and nongovernment representatives and would reflect their stakes in global challenges, not their cash contributions to the facility. 


\section{Box 6.1 What Young Development Professionals Think About Financing Development}

Benedikt Signer, Global Facility for Disaster Reduction and Recovery

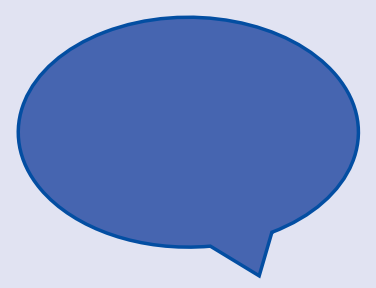

To support the achievement of vital global public goods (GPGs), as outlined in this book and for development as a whole (in any case often overlapping agendas), the World Bank cannot maintain an edge through financing volumes alone. Instead, it is about targeting available funds more effectively.

The comparative advantage of the World Bank cannot come solely from the financing it has available, nor from the knowledge and experience it has accumulated. While both are necessary, neither by itself is sufficient. Change has to be the defining feature as the Bank looks toward 2025 - not for the sake of self-perpetuation, but to fill an important void in the 21 st century. Faced with global challenges, it should support the necessary knowledge, capacity, and incentives for governments to put the long term at the heart of decision making, invest in public goods, and enable global collective action.

Investing in GPGs means investing for the long term. Spending resources now for future benefits requires trade-offs, and policy makers-in developed and developing countries alike-are faced with difficult political choices. In the face of pressing immediate needs and opportunity costs, competing priorities, and high discount rates, every decision to invest in the long term is inherently political. The Bank's work should support this process, by giving decision makers the tools to ask the right questions, to evaluate different strategies, and to make better-informed decisions.

Additionally, the Bank can support developing countries escape the false dichotomy between investing for today or for the future. Financing short-term development interventions linked to policies with long-term benefits can help overcome trade-offs. It can compensate countries that are willing to turn to more expensive alternatives that contribute to the achievement of GPGs for the difference in cost so as not to compromise their development.

Many of the challenges the world faces in the 21 st century are increasing in severity. Actions will get more costly over time, and in many cases we risk passing irreversible thresholds. Considering the impact of our actions today on future generations has to be a guiding principle as we look to achieve the highest impact with limited resources. Through funds well targeted, the World Bank can support national governments to make difficult choices now and leverage development processes over the long term.

\section{Role of Global Partnership Programs}

The Global Facility for Disaster Reduction and Recovery GFDRR, for instance, provides an example of how the World Bank can support vulnerable countries to consider the longterm effects in their decisions today. Rising disaster losses are mainly driven by increasing exposure of assets and people to natural hazards. A changing climate will exacerbate this further. GFDRR financing supports governments with the knowledge, tools, and supporting institutions to integrate risk considerations in long-term planning and investments 
across all sectors. Targeting limited finances strategically helps countries plan for the long term, to reduce existing risk, and prevent the creation of new risk.

The joint GFDRR-World Bank Disaster Risk Financing and Insurance (DRFI) Program is a good example how small, well-targeted Bank investments can catalyze larger reforms. In the context of increasing exposure to disaster risks and climate variability, there is an urgent need for governments to better understand, manage, and reduce the financial and fiscal impacts natural disasters inflict. Through the DRFI Program, GFDRR partners with countries to help increase their financial resilience, be better prepared for future uncertainty, and become less dependent on donor support.

Having access to cost-effective and rapid liquidity immediately after a disaster and the budgetary mechanisms to execute disbursements wisely can speed recovery, safeguard assets, minimize budget disruption, and reduce the total economic and human cost of the event. In addition, implementing a disaster-risk financing and insurance strategy also introduces discipline, transparency, and a long-term perspective in financial planning and supports comprehensive approaches to risk management through putting a price on risk.

Targeting limited funds to support governments prepare for the future is a win-win investment. It allows the World Bank to invest today in support of its core mission of poverty reduction, while supporting long-term thinking to ensure we are better prepared for future challenges than current behavior suggests.

\section{Notes}

1. Some relevant expenditures are already captured in the OECD's category of official development finance (ODF), which takes a receiver's perspective and includes the following receipts except where not provided for developmental purposes: bilateral ODA, concessional and non-concessional financing from multilateral financial institutions, and other official flows whose grant element is too low for them to qualify as ODA. ODF does not include non-ODA expenditures by bilateral development financing institutions, which appears to be the reason for the call for a new measure of total official support for development.

2. Namely, that the loan in question must convey a grant element of at least 25 percent based on a discount rate of 10 percent. The discount rate is much higher than prevailing interest rates and was set long ago on the basis of the presumed opportunity cost to the donor of providing the loan.

3. In 2012 a country was considered high-income if its per capita income exceeded $\$ 12,615$.

4. This was not always the case. For many years, the DAC counted only 77 percent of contributions to the GEF as ODA. However, this reflected the fact that some of its recipients were economies in transition, not the fact that some of the benefits of its investments were global benefits.

5. For a fuller but still non-technical account, see "Is it ODA?" (OECD 2008).

6. The DAC maintains and regularly revises lists of developing countries and international development organizations.

7. Interest is not included as negative ODA on the basis that in constant price terms, its inclusion would cause total reflows to exceed the size of the loan originally recorded 
as ODA, thus creating a net loss for the donor. However, Tew (2013) has noted that when one looks at the situation from the receivers' perspective, the exclusion of interest causes ODA receipts to be overstated quite substantially.

8. The DAC in fact has devised two such concepts: ODF, already mentioned, and country programmable aid (CPA), which is used to measure a subset of aid inflows from bilateral and multilateral sources to developing countries. CPA is a quite restricted concept, limited to actual flows available for long-term development financing, and accounts for around half of all ODA.

9. There can be a substantial time lag between the provision of contributions to multilateral organizations and the consequent flow of resources from those organizations to developing countries.

10. This is a term suggested in Severino and Ray (2009).

11. Such public goods need not be the exclusive domain of national governments, though in general they will be the primary providers.

12. Some aid is used as direct support for business ventures in developing countries, but it is almost insignificant in quantity. The jury is out as to whether such support is worthwhile, with many people arguing that aid for private sector development should be confined to the provision of relevant public goods.

13. This leaves outflows from special-purpose trust funds aside.

14. Grace (2006) is a partial counter example. The U.K. Department for International Development commissioned Grace to advise on the relative merits of "push" vs. "pull" mechanisms in health in order to inform resource allocation decisions.

15. Some of these are funds to which the World Bank has contributed through the Development Grant Facility, rather than funds that the Bank itself manages.

16. "Social impact bonds" are being piloted in a number of developed countries, including Australia, the United Kingdom, and the United States. The Center for Global Development has explored the idea of extending the model for international development purposes (CGD 2013). The term "bond" is something of a misnomer, as returns to investors are not fixed.

17. For example, an Independent Evaluation Group evaluation of the Medicines for Malaria Venture, to which the Bank contributes, found MMV to be successful but was less positive about the value of the Bank's engagement with it.

18. A global Development Bank for Infrastructure and Sustainable Development was proposed in 2012 by Bhattacharya, Romani, and Stern (2012).

19. These bonds might be identified with the various specific problems to be tackled with support from the facility on the model of vaccine bonds (issued by IFFIm) or green bonds (issued by the IBRD).

\section{References}

Bhattacharya, Amar, Mattia Romani, and Nicholas Stern. 2012. "Infrastructure for Development: Meeting the Challenge." Policy Paper, Centre for Climate Change Economics and Policy and the Grantham Research Institute on Climate Change and the Environment, in collaboration with the Intergovernmental Group of Twenty-Four, London. 
CGD (Center for Global Development). 2013. "Investing in Social Outcomes: Development Impact Bonds." Report of the Development Impact Bond Working Group. Published jointly with Social Finance, CGD, Washington, DC.

DI (Development Initiatives). 2013. Guide to Official Development Assistance. Development Initiatives, Bristol, U.K.

Grace, Cheri. 2006. Developing New Technologies to Address Neglected Diseases: The Role of Product Development Partnerships and Advanced Market Commitments. DFID Health Resource Centre, U.K. Department for International Development, London.

G20. 2010. "Seoul Development Consensus for Shared Growth." Annex I to leaders' communique, G20 Seoul summit, November 11-12.

. 2008. Annual Review of Development Effectiveness 2008: Shared Global Challenges. IEG, Washington, DC: World Bank.

2011 a. Trust Fund Support for Development: An Evaluation of the World Bank's Trust Fund Portfolio. Washington, DC: World Bank.

. 201 lb. The World Bank's Involvement in Global and Regional Partnership Programs: An Independent Assessment. Washington, DC: World Bank.

OECD (Organisation for Economic Co-operation and Development). 2008. "Is it ODA?" Supplement to OECD Development Assistance Committee (DAC) Statistical Reporting Directives. OECD, Paris.

_. 2012. "Communique of the 2012 High-Level Meeting of the OECD Development Assistance Committee.” OECD, Paris.

Severino, Jean-Michel, and Olivier Ray. 2009. "The End of ODA: Death and Rebirth of a Global Public Policy.” Working Paper 167, Center for Global Development, Washington, DC.

Tew, Rob. 2013. "ODA Loans: Investments to End Poverty Discussion Paper." Development Initiatives, Bristol, U.K.

UN (United Nations). 2000. "Millennium Declaration." Resolution A/RES/55/2 adopted by the General Assembly at its 55th Session, September 2000.

World Bank. 2007. "Global Public Goods: A Framework for the Role of the World Bank." Paper prepared by staff of the World Bank for the Development Committee, October. World Bank, Washington, DC.

World Health Organization. 2001. "Macroeconomics and Health: Investing in Health for Economic Development." Report of the Commission on Macroeconomics and Health. Geneva. 